\title{
Importance of stream temperature to climate change impact on water quality
}

\author{
A. Ducharne \\ Laboratoire Sisyphe, CNRS/Université Pierre et Marie Curie, Paris, France \\ Received: 17 July 2007 - Published in Hydrol. Earth Syst. Sci. Discuss.: 25 July 2007 \\ Revised: 23 April 2008 - Accepted: 23 April 2008 - Published: 23 May 2008
}

\begin{abstract}
The sensitivity of some aspects of water quality to climate change was assessed in the Seine River (France) with the biogeochemical model RIVERSTRAHLER, which describes the transformations and fluxes of $\mathrm{C}, \mathrm{N}, \mathrm{P}$ and $\mathrm{Si}$ between the main microbiological populations, the water column and the sediment, along the entire river network. Point and diffuse sources are prescribed, stream temperature undergoes a sinusoidal annual cycle constrained by observations, and runoff is calculated by a physically-based land surface model. The reference simulation, using meteorological forcing of 1986-1990 and point sources of 1991, compares very well with observations. The climate change simulated by a general circulation model under the SRES emission scenario A2 was used to simulate the related changes in runoff and stream temperature. To this end, a statistical analysis was undertaken of the relationships between the water and air temperatures in the Seine watershed over 1993-1999, using 88 points that correctly sampled the variability of the tributaries. Most of stream temperature variance was explained by the lagged moving average of air temperature, with parameters that depended on Strahler stream order. As an interesting simplification, stream temperature changes could be approximated by air temperature changes. This modelling framework was used to analyse of the relative influence of the water warming and discharge reduction induced by climate change on biogeochemical water quality in Paris and downstream. Discharge reduction increased phytoplankton growth and oxygen deficits. Water warming decreased dissolved oxygen, increased phytoplankton biomass during the growth period, and reduced it afterwards, when loss factors dominate. It was also shown that these impacts were enhanced when point source inputs of nutrient and organic carbon increased.
\end{abstract}

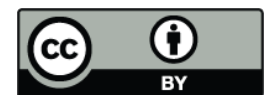

Correspondence to: A. Ducharne (agnes.ducharne@upmc.fr)

\section{Introduction}

Climate change impacts on river systems are the subject of active research (as reviewed by Arnell et al., 2001), because of the importance of water for human activities, in terms of resource (quantitatively and qualitatively) and risk factor. Impacts on hydrology include changes in runoff, river flow and groundwater storage. Water quality can also be impacted, through its many facets (physical, including temperature and turbidity; chemical, including $\mathrm{pH}$ and concentrations; biological, including biodiversity and species abundance, across the entire food web from microbial pools and macrophytes up to fishes).

Focus is put on the so-called biogeochemical water quality, defined by the in-stream concentrations of nutrient, organic carbon and oxygen on the one hand, and of the planktonic biological pools on the other hand, which combine for instance to control eutrophication. With respect to this biogeochemical water quality, most climate change impacts can be attributed to changes in either discharge, which controls dilution, flow velocity and residence times, or in water temperature. When the latter increases, oxygen diffusion to the water column decreases, and biological activity is enhanced, with consequences on nutrients, organic matter and biomass. The impact of climate change on river water quality is also heavily dependent on the future evolution of human activities (pollutions, withdrawals, etc.), so that the direct effect of climate change may end up being small in relative terms (Hanratty and Stefan, 1998; Ducharne et al., 2007).

These issues are addressed here in the case study of the Seine River basin. It is a representative example of human influenced regional watersheds, and there is a wealth of research and background information to draw on, owing to the PIREN-Seine programme, a large interdisciplinary research program on the Seine River System, jointly funded since 1989 by the French CNRS and the Water Authorities of the Seine basin (Billen et al., 2007). The potential impacts of

Published by Copernicus Publications on behalf of the European Geosciences Union. 


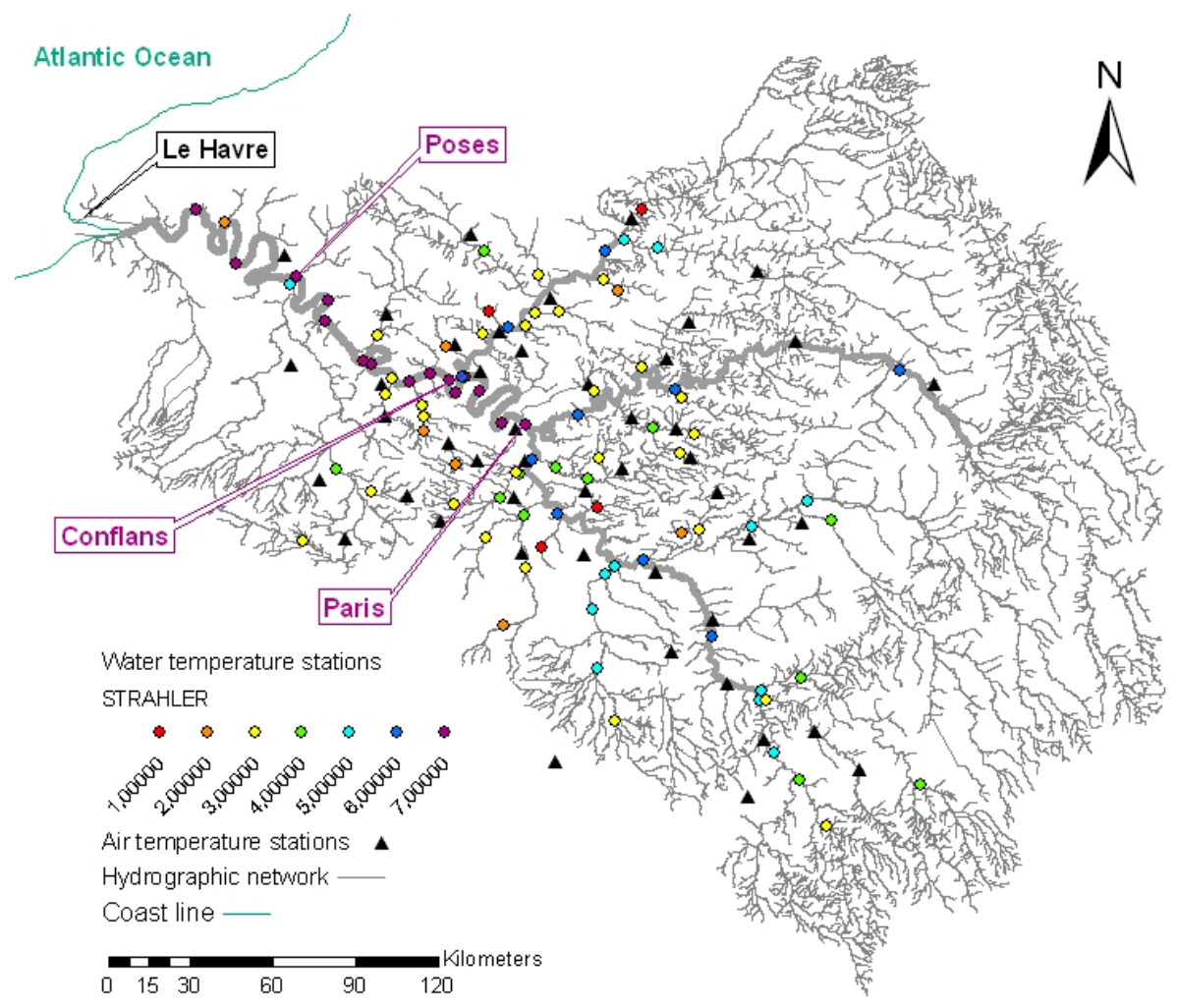

Fig. 1. Map of the Seine River basin, locating the monitoring stations of air and water temperature. The colours of the latter indicate the Strahler order at the water temperature measurement stations. The hydrographic network appears in grey and is thicker at Strahler orders 6 and 7. The Seine has an order 7 at Conflans, as in Paris, but the corresponding dot is masked by the one of the most downstream station on the Oise tributary, of order 6.

future changes of climate and anthropogenic pressures were compared there by Ducharne et al. (2007). To this end, four validated physically-based models, addressing separate components of the river system (agronomical model, hydrogeological model, land surface model and river biogeochemical model), were used sequentially to assess the relative impact of climate, land-use and point-source inputs on biogeochemical water quality. This study shows that the reduction of point-source inputs that can be postulated by the middle of the 21 st century, following the ongoing trends to improved collection and treatment of wastewater, is the first-order driving factor of biogeochemical water quality over the 21 st century, leading to a noticeable decrease in eutrophication and oxygen deficits downstream from Paris. The impact of climate change is only secondary and driven by the warming of the water column.

The present paper aims at providing a deeper insight with respect to the influence of water temperature to biogeochemical water quality in the context of climate change, using a simpler numerical framework (Sect. 3). After an overview of the Seine River basin during the reference period of 19861990 (Sect. 2), the selected climate change scenario and its impact on runoff are presented (Sect. 4). The way to ac- count for the related water temperature changes is detailed in Sect. 5, and Sect. 6 provides an analysis of the relative influence of water warming and discharge changes to biogeochemical water quality in Paris and downstream, and how this influence is modulated by nutrient and organic carbon loads.

\section{The Seine River basin}

This modelling work was conducted in the Seine River basin $\left(78600 \mathrm{~km}^{2}\right)$ in the northern part of France (Fig. 1). The Seine River is $776 \mathrm{~km}$ long at Le Havre, its outlet to the Atlantic Ocean, but the estuary begins at Poses, $166 \mathrm{~km}$ upstream from Le Havre. The Seine River network is embedded in the sedimentary basin of Paris, with numerous aquifer layers, which are important to water resources and significantly sustain low flows. The altitude ranges from 0 to $856 \mathrm{~m}$ above sea level but $90 \%$ of the basin is below $300 \mathrm{~m}$, so that the slopes of streams are moderate and climate does not exhibit sharp geographical gradients. The mean annual precipitation (750 mm/y over 1931-1960; AESN, 1976) is minimum in the centre of the basin $(430 \mathrm{~mm} / \mathrm{y})$ and exceeds $850 \mathrm{~mm} / \mathrm{y}$ in the coastal zone and the south-eastern hills (Morvan). Rainfall 
is very uniformly distributed throughout the year and snow influence is negligible, so that the hydrological regime of the Seine and its tributaries is a pluvial oceanic regime, modulated by the seasonal variations of evapotranspiration. This leads to high flows in winter and low flows in summer, sustained by base flow from the aquifer system and by the hydraulic management of the main tributaries.

As revealed by the land use map Corine Landcover version 1990 (EEA, 1996), which results from the analysis of Landsat and Spot satellite images from 1987 to 1994, land use is dominated by agriculture, with arable land, grassland and woodland covering $51 \%, 18 \%$ and $25 \%$ respectively of the watershed. The Seine watershed (14\% of the area of metropolitan France) gathers about 15 million inhabitants (ca. $25 \%$ of the national population), but the population density is very heterogeneous. Most urban areas are concentrated along the main tributaries and the estuary, and the Parisian region $\left(2500 \mathrm{~km}^{2}\right)$ concentrates more than 10 million inhabitants. The Seine watershed comprises $40 \%$ of the national industrial activities, also largely concentrated along the main tributaries and the estuary. To protect these areas, including Paris and the Parisian region, from disastrous floods such as experienced in 1910 or 1955, and to sustain low flows in summer, the construction of reservoirs upstream from Paris was initiated in the 1930's, and the main three reservoirs presently operational have been constructed on the Aube, Marne and Seine rivers between 1966 and 1989 (Meybeck et al., 1998).

To summarize these features, the main water-related issue in the Seine watershed for the time being is not about water resources but water quality, which suffers from diffuse pollution from agriculture (nitrate, pesticides) and from point source pollution to rivers, because of the heavy urbanisation and related industrial activity.

\section{Modelling of water quality in the Seine River}

\subsection{The RIVERSTRAHLER model}

The RIVERSTRAHLER model (Billen et al., 1994; Garnier et al., 1995; Garnier et al., 1999) calculates the spatial and seasonal variations of discharge and some aspects of water quality and ecological functioning within entire river network, from headwaters to the outlet. It accounts for the constraints set by river morphology, hydrometeorology, diffuse sources from the watershed, and point source pollution from wastewater treatment plants (WTP) and industries. RIVERSTRAHLER describes the drainage network as a combination of three components: (i) in upstream basins, the river network is simplified as a regular scheme of confluence of tributaries of increasing stream order, each characterised by mean morphological properties; (ii) in the main streams, the morphology is represented realistically, with a spatial resolu- tion of $1 \mathrm{~km}$; (iii) ponds or reservoirs are taken into account as mixed reactors connected to the other components.

Unless otherwise mentioned, water quality in the rest of the paper will be used as a surrogate term for the ensemble of 23 state variables simulated by RIVERSTRAHLER within the entire river network. They comprise the concentrations of oxygen, nutrients $\left(\mathrm{NH}_{4}^{+}, \mathrm{NO}_{3}^{-}, \mathrm{PO}_{4}^{3-}\right.$, particulate inorganic phosphorus and $\mathrm{SiO}_{2}$ ), suspended solids and organic carbon (particulate and dissolved under three classes of biodegradability). Other state variables quantify the biomass (in $\mathrm{mgCl}^{-1}$ ) of the main planktonic pools, with two taxonomic groups of phytoplankton (diatoms and non-diatoms), two kinds of zooplankton (rotifers and microcrustaceans), heterotrophic and nitrifying bacteria. The exchanges of organic carbon, nutrients and oxygen across the sediment-water interface are also accounted for, as the impact of viruses and benthic filters, represented by constant rates modulated by temperature.

The set of equations describing the kinetics of these variables is known as the RIVE model. Under the assumption of unity of the aquatic continuum (Vannote et al., 1980), these kinetics are described with the same parameters from headwaters to the outlet, and these parameters are mostly set from direct experimental determination. Thus, the spatialtemporal variations of the simulated biogeochemical water quality are only controlled by the boundary conditions of the river network.

River flow, depth and velocity are estimated at the 10-day time step from runoff (expressed per unit area), routed as a function of river morphology using the Manning-Strickler formula. The composition of surface runoff and base flow, assumed constant over seasons, is characterised as a function of land use and lithology of the unit catchments, thus representing the diffuse sources to the river network. Water temperature and incoming radiation are described by a sinusoidal annual cycle constrained by recent observations. The latter is modulated by nebulosity and a water extinction coefficient to define the photosynthetically active radiation for phytoplankton growth.

\subsection{Modelling of runoff and diffuse nitrate sources}

The version of RIVERSTRAHLER used in this study was exactly the same as in Ducharne et al. (2007). In particular, important boundary conditions were provided by other models, namely runoff and the diffuse sources of nitrate from agriculture, likely to change significantly during the 21 st century because of climate change. As argued in Ducharne et al. (2007), these boundary conditions are modelled using physically-based models, with limited and documented calibration, in order to guarantee, as much as possible, the transferability to situations that have never been experienced thus monitored. The diffuse sources of nitrate were simulated by the STICS-MODCOU modelling chain (Ledoux et al., 2007), which couples a crop model to a hydrogeological 
model to describe nitrate leaching from agricultural soils and nitrate concentration, in base flow from the groundwater system and in surface runoff.

These two terms of runoff, used by RIVERSTRAHLER to derive river flow, are simulated by the catchment-based land surface model (CLSM; Koster et al., 2000; Ducharne et al., 2000). As all land surface models (LSMs), it is designed to simulate the diurnal cycle of land surface water and energy fluxes as a function of near-surface meteorology (precipitation, short-wave and long-wave incident radiation, surface pressure, air temperature and humidity at $2 \mathrm{~m}$, wind speed at $10 \mathrm{~m}$ ) and can either be coupled to a general circulation model (GCM) or used off-line as in the present study. The CLSM belongs to a new generation of LSMs which rely on the concepts of the hydrological model TOPMODEL (Beven and Kirkby, 1979) to account for lateral water fluxes along topography, their influence on the small scale variability of soil moisture, runoff and evapotranspiration, thus on larger scale water budget.

The simulated domain is discretised into unit hydrological catchments, all including a water table. Following TOPMODEL, a high-resolution digital elevation model (DEM) is used to characterise the distribution of a topographic index in each unit catchment. It serves as a template to laterally redistribute the water table depth around its mean value, which varies in time as a result of the catchment water budget. The water table distribution is used to partition the catchment into three fractions, each with a different moisture stress, and thus a different runoff and evapotranspiration, according to classic soil-vegetation-atmosphere transfer (SVAT) formulations. The water table distribution also controls the water fluxes to and from the water table, namely the exchanges with the root zone and the base flow to the streams.

\subsection{Validation in 1986-1990}

The Seine watershed upstream Poses was subdivided into 27 unit catchments, with an average size of $2600 \mathrm{~km}^{2}$. Catchment delineation and topographic index computation for the CLSM were based on a 100-m resolution DEM. Soil and vegetation properties were defined as in Ducharne et al. (2007), with only three calibrated parameters, namely the wilting point and the two parameters describing the vertical profile of saturated hydraulic conductivity. Surface runoff and base flow were simulated by the CLSM over five years (19861990), using meteorological forcing from the SAFRAN analysis, at a 1-h and 8-km resolution (Durand et al., 1993), interpolated by simple weighted means to the 27 unit catchments. The 10-day totals of surface runoff and base flow were provided to RIVERSTRAHLER which was run in the same 27 unit catchments, defining 14 upstream basins and 13 stream branches. RIVERSTRAHLER also described the main three regulation reservoirs constructed in the upstream part of the Seine, Aube and Marne watersheds, and their influence on the downstream streams.
Nitrate concentrations in groundwater and surface runoff were simulated using the STICS-MODCOU modelling chain, with land use (including crop rotations and technical calendars) representative of the decade 1990-2000 and meteorological data for 1970-1990, as provided by the SAFRAN analysis at the 1-day and 8-km resolution. Starting from zero nitrate in the groundwater, these boundary conditions were repeated for 50 years until nitrate concentration in the groundwater reached values that were representative of the ones actually surveyed in 2000 . The resulting nitrate concentrations, in both groundwater and surface runoff, originally designed to provide the initial conditions for long-term simulations over the 21st century, were used as input to RIVERSTRAHLER, after being reduced to account for riparian retention. Because of the ongoing accumulation of nitrate in the groundwater, estimated as $0.64 \mathrm{mg}^{-1} \mathrm{y}^{-1}$ by Ledoux et al. (2007), these underground diffuse sources were overestimated for the period 1986-1990 simulated here with RIVERSTRAHLER. As nitrate concentrations, however, were already too high to be limiting during this period, this error does not propagate to the other terms of the simulated water quality.

Point source input to the river network were described by the location and load of each point source along the river network in 1991, mapped from the data provided by the watershed agency, the Agence de l'Eau Seine-Normandie. These data are based on declarations to the agency, by territorial administrations for domestic sources (waste water treatment plants and direct discharge) and by industries according to their sector and declared level of activity. The last boundary conditions of RIVERSTRAHLER, water temperature and incoming radiation, were described by a sinusoidal annual cycle constrained by recent observations, as already mentioned.

The resulting simulation compares well with observed river quality parameters during 1986-1990, as illustrated in Paris and Conflans (Fig. 2). These two stations are only distant of $75 \mathrm{~km}$ on the Seine River, which is not influenced by any significant confluence between them (Fig. 1). As a result, they share a very similar discharge and water temperature. Simulated low flows are correctly sustained in dry years (1989 and 1990), and the contrast with the very large flood of winter 1988, an interesting sample of inter annual variability, is satisfactorily reproduced, despite a trend to overestimated high flows. The seasonal cycle of water temperature has a correct phase and amplitude, and it does not exhibit significant inter annual variability during the five simulated years, which is realistic compared to observations.

The main difference between Paris and Conflans is related to massive point source inputs between then, in particular from the Achères WTP, which collects the domestic effluents from 6 million inhabitants of the Paris conurbation. This explains the marked increase in nutrient and organic carbon between the two stations. The increase in nutrient concentration, illustrated by phosphate and ammonium, combines with the increase of residence time in the river between the two 

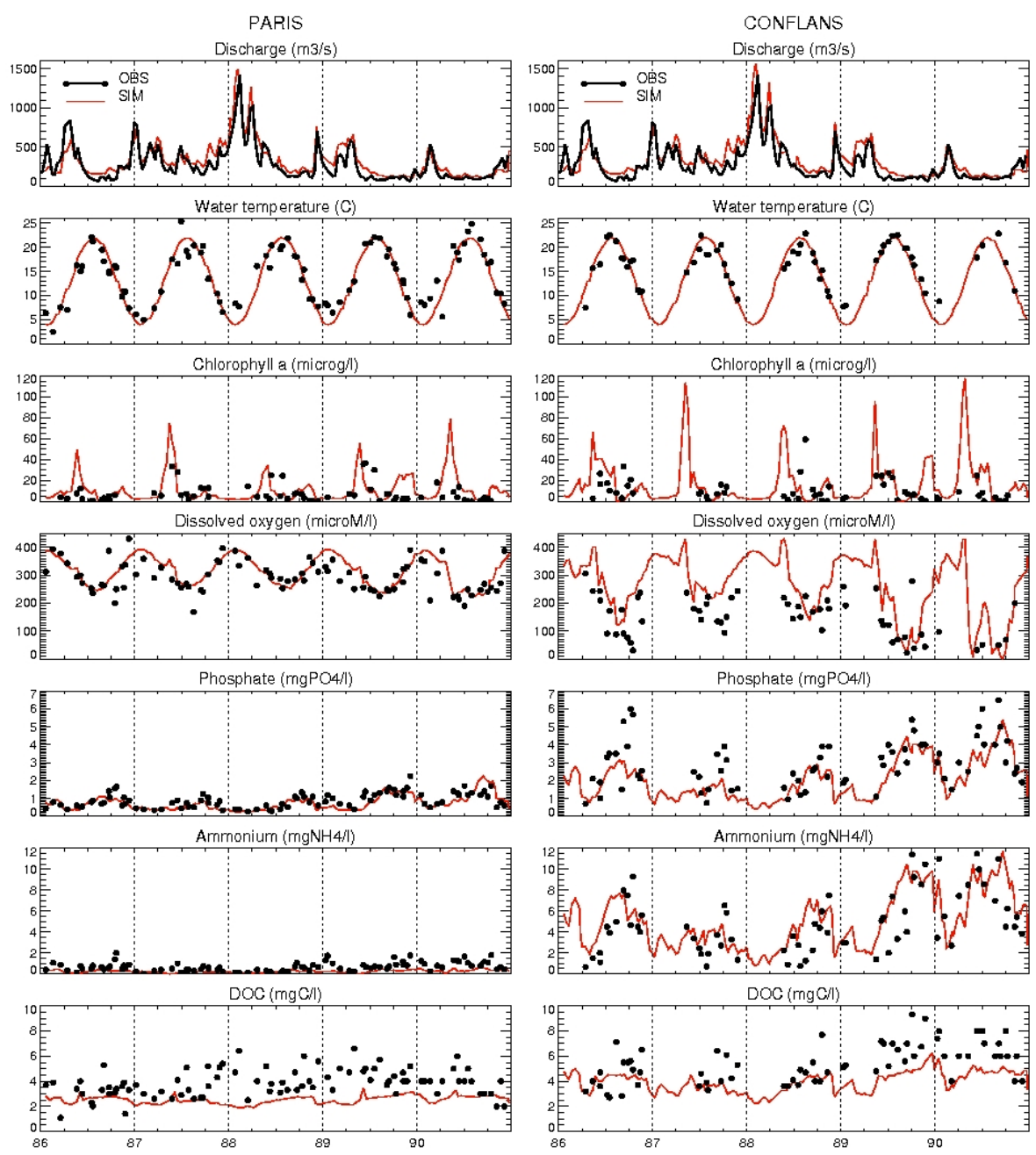

Fig. 2. Validation of the discharge and biogeochemical water quality simulated by RIVERSTRAHLER coupled to CLSM in 1986-1990, in Paris and Conflans: comparison of observations (black dots; source: Réseau National de Bassins) with the water quality simulated using point sources of year 1991. Chlorophyll a is proportional to phytoplankton biomass (Garnier et al., 1995). DOC stands for dissolved organic carbon. Discharge is not measured at Conflans, and the observed values at Paris are used instead, as the upstream contributing areas to the two stations are almost identical.

stations, to explain the higher phytoplankton biomass simulated in Conflans. This difference may be slightly overestimated by the model, but it must be noted that sampling frequency of chlorophyll- $a$, used as a proxy to phytoplankton biomass (Garnier et al., 1995), is not sufficient to correctly capture the phytoplankton blooms. As in the rest of the paper, organic carbon is illustrated by dissolved organic carbon (DOC). It is slightly overestimated by RIVERSTRAHLER, but this model realistically simulates that DOC is mainly non biodegradable (70\% in Paris and 60\% in Conflans) and that it comprises two thirds of total organic carbon. The increase in organic carbon and ammonium between Paris and Conflans explains the much more severe oxygen deficits in Conflans, and the differences between the two stations are well simulated by the model. Also well simulated is the influence of discharge on the concentrations of nutrient, organic carbon and oxygen, shown by the highest nutrient concentrations and oxygen deficit during the summers of 1989 and 1990.

Further validation of this version of RIVERSTRAHLER was provided in Ducharne et al. (2007) at Poses, the most downstream station before entering the estuarine domain, thus downstream from Paris and the related point source input to the river. In particular, this work shows the good performance of the model to reproduce dissolved silica concentrations, which cannot be assessed in Paris and Conflans by lack of observations. Among many other validation exercises, RIVERSTRAHLER, in a different but rather close version, was used to reconstruct the evolution of water quality in the Seine River over the last 50 years (Billen et al., 2001), providing ample evidence of its ability to reproduce observed variations of water quality variables under contrasting hydrometeorological conditions. 


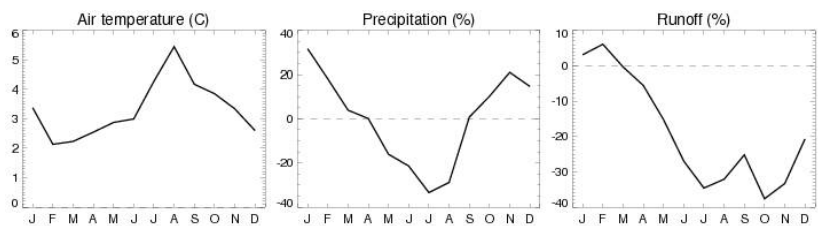

Fig. 3. Monthly mean anomalies between the climate change and reference scenarios (A2-REF), on average over the entire Seine watershed, for temperature (in ${ }^{\circ} \mathrm{C}$ ), precipitation and runoff simulated by the CLSM (relative anomalies in \% of the monthly mean reference value).

\section{Climate and runoff changes}

\subsection{GCM climate change scenario}

Climate change was described using two 30-year simulations performed with the variable resolution GCM ARPEGE-IFS cycle 18 (Gibelin and Déqué, 2003). The global resolution was refined around the centre of the Mediterranean Sea $\left(40^{\circ} \mathrm{N} ; 12^{\circ} \mathrm{E}\right)$ leading to a resolution of about $50 \mathrm{~km}$ in the Seine watershed. The simulations corresponded to 1960 1989 and 2070-2099 and were driven by the SRES-A2 scenario of radiative forcing, leading to a greenhouse gas concentration equivalent to $850 \mathrm{ppm}$ of $\mathrm{CO}_{2}$ at the end of $21 \mathrm{st}$ century. Sea surface temperatures (SSTs) were prescribed from monthly observations for the recent climate simulation. For the climate change simulation, these observations were blended with SSTs from ocean-atmosphere coupled simulations. The resulting global annual atmospheric warming at $2 \mathrm{~m}$ simulated between 1960-1989 and 2070-2099 was $2.3^{\circ} \mathrm{C}$.

Gibelin and Déqué (2003) also showed that the recent climate simulation reproduced the main climate characteristics over the Mediterranean region, despite a winter overestimation of rainfall in north-western Europe. A specific validation was conducted in the Seine watershed over 1970-1989 (Ducharne et al., 2007). The 2-m temperatures were accurately simulated, but the wet bias of winter precipitation was confirmed, leading to an annual mean overestimation of $+35 \%$ over the basin.

\subsection{Downscaled climate change scenario}

The near surface meteorological variables required as input to the CLSM to simulate runoff changes were available at the daily time step from the two GCM simulations. The spatial resolution of the GCM was sufficient compared to the one of the CLSM (44 GCM grid cells in the Seine watershed vs. 27 unit catchments) and spatial interpolation to the catchment space was simply performed by averaging the GCM outputs, using the intersection fractions between the GCM cells and the unit catchments as weights. It was necessary, however, to correct for the GCM biases, especially those in precipitation that propagate to runoff (Ducharne et al., 2003), and to downscale the GCM output to the hourly time step of the CLSM. As described in Ducharne et al. (2007), we used a simple technique for bias correction and downscaling, the perturbation method.

The reference, or baseline, scenario, called REF, is made of the entire SAFRAN meteorological forcing used for the validation simulation described in Sect. 3.3. This data set, with a 1-h time step, and interpolated to the 27 unit catchments of the CLSM from its native $8-\mathrm{km}$ resolution, covers five years (1986-1990). This period was selected because hourly data were not available before August 1985, and we chose to exclude the 1990's decade, which was the hottest since 1860, and even likely during the last millennium (Houghton et al., 2001), and was probably not independent of climate change. Then, after interpolation of the GCM output to the 27 unit catchments, we computed the interannual monthly mean of each meteorological parameter, for both the climate change and recent climate GCM simulations. We defined monthly climate perturbations as the difference in interannual monthly mean for temperature and their ratio for the other parameters, and we applied these monthly perturbations to the baseline parameters, to all time steps within the selected month.

On average over the watershed, the differences between the climate change scenario, called A2, and the reference scenario comprise an increase in near surface temperature, which amounts to $+3.3^{\circ} \mathrm{C}$ on annual mean and is systematic over the year, although more pronounced in summer (Fig. 3). In contrast, the annual mean precipitation does not change significantly $(+0.1 \%)$ but this results from a tradeoff between marked winter increase and summer decrease. Other changes include increased atmospheric radiation, as a result of increased greenhouse effect, and increased solar radiation in summer, by means of reduced rainfall and cloudiness. Combined to the temperature increase, they induce an increase in potential evapotranspiration (Ducharne et al., 2007).

\subsection{Subsequent runoff change}

The CLSM responds to this increased potential by an increase in actual evapotranspiration $(+5 \%$ on interannual mean over the watershed). Note that the CLSM does not account for the possible reduction of stomatal conductance and transpiration because of increased $\mathrm{CO}_{2}$ concentration. Increased evapotranspiration drives a decrease of the watershed moisture in summer, which is enhanced by the seasonal decrease in precipitation, and propagates in winter, when it limits the impact of increased winter precipitation onto runoff. As a result, the CLSM simulates a decrease in mean runoff $(-11 \%$ over the watershed), with enhanced seasonal contrasts, consisting in a small increase in winter and a massive decrease in low flow periods, exceeding $-35 \%$ in July and October (Fig. 3). 


\section{Modelling of stream temperature change}

\subsection{Methods and data}

If climate change impact on runoff can be simply simulated by the CLSM from a climate change scenario, a method was needed to estimate the related water temperature change. Following many authors (e.g. Stephan and Preud'homme, 1993; Webb and Nobilis, 1997; Caissie et al., 1998), we established a linear regression model between air temperature and water temperature. These simple models, which highlight air temperature as a surrogate for changes in heat fluxes that affect the water surface, achieve to explain a high level of the water temperature variance. Because of the high heat capacity of water, water temperature variations often tend to lag behind those of air temperature. This effect was shown to be more pronounced in larger rivers (Stephan and Preud'homme, 1993) and can be explained by the convergence of water temperature towards equilibrium temperature (i.e. the temperature of the water mass when a stationary regime is achieved with the atmospheric conditions, so that there is no energy flux with the atmosphere anymore) as water flows downstream (Mohseni and Stefan, 1999).

The width and depth of streams tend to increase in the downstream direction and can be related to Strahler stream order, as performed in the upstream basins of RIVERSTRAHLER (Billen et al., 1994). In the Strahler ordering scheme (Strahler, 1957), stream order is 1 at the headwaters and increases toward the outlet of the watershed. When two $n$-th order streams come together, they form an $(n+1)$-th order stream, but the confluence with streams of lower order does not change the order of the highest order stream. The Strahler order of the Seine River network's tributaries was characterized using the Arcview 9.1 Geographical Information System, leading to a maximum order of 7 at the outlet (Fig. 1).

In an attempt to generalize the findings by Stefan and Preud'homme (1993), we established linear relationships between water temperature (WT) on the one hand and the lagged moving average of air temperature $(A T)$ on the other hand, with parameters (slope $a$, y-intercept $b$, and lag $L$ ) that depend on Strahler stream order, designated by the index $i$ :

$W T=a_{i} m\left(A T, L_{i}\right)+b_{i}$.

In the above equation, the moving average operator $m$ gives the mean of $A T$ over the $L_{i}$ days that precede the measurement of $W T$. The dependence on stream order had the further advantage of being easily amenable to the spatial framework of the RIVERSTRAHLER model.

An important question when using a statistical model is its transferability to conditions that are different from the ones prevailing for the characterization of its parameters. These parameters need to be fitted locally, as they implicitly account for all the local characteristics that are not explicated

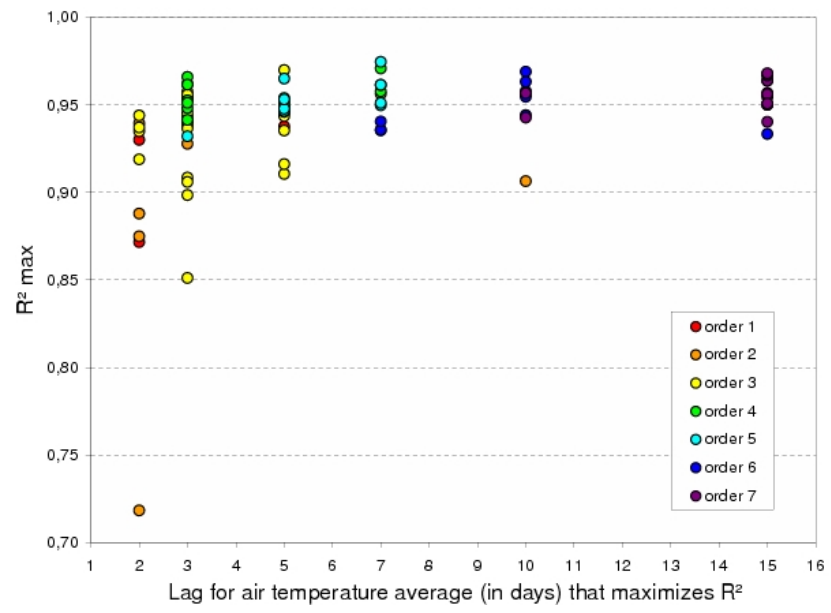

Fig. 4. Lags used in the moving average of $A T$ that maximize the determination coefficient $R^{2}$ between $W T$ and lagged $A T$, for each of the 88 couples of WT-AT measurement stations. The colour of the dots indicates the Strahler order of the WT station.

by the model, so that they cannot be transferred to other geographical settings. The dependence on stream order that is demonstrated below is an interesting advance with this regard. In contrast, transferability to other periods is possible if the boundary conditions can be supposed stationary, which is of course not the case when dealing with climate change. As it is impossible to characterize parameters in climate change conditions, as they have not occurred yet, necessity leads us to look for the recorded period that is the closest to climate change conditions, namely the warmest. This study was thus performed for the period 1993-1999, as the 1990's decade was the hottest in history, and continuous records of hourly $A T$ measurement from the synoptic network of Météo-France were available in 46 stations of the Seine River basin (Fig. 1).

WT is recorded at sampling stations of the RNB (Réseau National de Bassin) network, where numerous other water quality parameters are monitored since 1971. The Seine River basin contains more than 1600 RNB stations, rather well distributed in the basin but the sampling frequency varies between 0 to 24 observations per year depending on years and stations. We selected $W T$ stations in a $40-\mathrm{km}$ radius from an $A T$ station, with at least $12 W T$ measurements per year for at least 5 years during the 7-year period of analysis, 1993-1999. As a result, 88 WT stations were investigated in the Seine watershed, which correctly sampled the variability of the tributaries with respect to stream order (Fig. 1, Table 1). The mean distance between $A T$ and $W T$ stations is $11.7 \mathrm{~km}$, with a standard deviation of $6.8 \mathrm{~km}$ and a maximum of $36.5 \mathrm{~km}$.

\subsection{Results}

For each of the 88 couples of $A T-W T$ stations, linear regressions were performed between $W T$ and the lagged moving 
Table 1. Relationships of observed water temperature $(W T)$ to observed air temperature $(A T)$ and calculated $W T$ in the Seine basin: mean values as a function of Strahler order.

\begin{tabular}{|c|c|c|c|c|c|c|c|c|}
\hline & & \multicolumn{7}{|c|}{ Strahler order } \\
\hline & & 1 & 2 & 3 & 4 & 5 & 6 & 7 \\
\hline & Number of $W T$ stations & 4 & 7 & 27 & 12 & 13 & 10 & 15 \\
\hline & Distance to $A T$ stations $(\mathrm{km})$ & 6.9 & 16.6 & 10.8 & 12.7 & 11.9 & 8.4 & 13.0 \\
\hline & Mean $W T$ & 11.86 & 12.02 & 12.00 & 12.20 & 12.86 & 13.26 & 13.97 \\
\hline \multirow{6}{*}{$\begin{array}{l}\text { Observed } W T \text { vs. best linear } \\
\text { function of lagged } A T\end{array}$} & Lag that maximizes $R^{2}$ (days) & 2.75 & 3.86 & 3.44 & 4.33 & 6.15 & 10.90 & 14.33 \\
\hline & Slope $a(-)$ & 0.64 & 0.68 & 0.73 & 0.79 & 0.88 & 0.98 & 1.06 \\
\hline & y-intercept $b\left({ }^{\circ} \mathrm{C}\right)$ & 4.56 & 4.25 & 3.82 & 3.35 & 3.00 & 2.08 & 1.97 \\
\hline & Resulting $R^{2}$ & 0.89 & 0.90 & 0.94 & 0.95 & 0.95 & 0.95 & 0.96 \\
\hline & Bias $\left({ }^{\circ} \mathrm{C}\right)$ & -0.11 & -0.14 & -0.19 & -0.21 & -0.19 & -0.23 & -0.18 \\
\hline & $\operatorname{RMSE}\left({ }^{\circ} \mathrm{C}\right)$ & 1.29 & 1.16 & 1.13 & 1.07 & 1.18 & 1.31 & 1.26 \\
\hline \multirow{6}{*}{$\begin{array}{l}\text { Observed } W T \text { vs. } \\
\text { calculated } W T\end{array}$} & Selected lag (days) & 2 & 3 & 3 & 5 & 7 & 10 & 15 \\
\hline & Slope $a(-)$ & 0.62 & 0.66 & 0.73 & 0.79 & 0.88 & 0.97 & 1.07 \\
\hline & y-intercept $b\left({ }^{\circ} \mathrm{C}\right)$ & 4.74 & 4.32 & 3.81 & 3.34 & 2.97 & 2.31 & 1.93 \\
\hline & $R^{2}$ & 0.88 & 0.89 & 0.93 & 0.95 & 0.95 & 0.95 & 0.96 \\
\hline & $\operatorname{Bias}\left({ }^{\circ} \mathrm{C}\right)$ & -0.10 & -0.29 & -0.20 & -0.23 & -0.20 & -0.26 & -0.15 \\
\hline & $\operatorname{RMSE}\left({ }^{\circ} \mathrm{C}\right)$ & 1.89 & 1.69 & 1.53 & 1.25 & 1.31 & 1.35 & 1.41 \\
\hline
\end{tabular}

average of $A T$, called lagged $A T$ for simplicity in the rest of the paper, using different lags: 2, 3, 5, 7, 10 and 15 days. We first identified the lags that were maximizing the determination coefficient $R^{2}$ between $W T$ and lagged $A T$. The resulting $R^{2}$ exceed 0.90 (respectively 0.95 ) in $93 \%$ (59\%) of the cases (Fig. 4). This demonstrates a strong linear relationship between $W T$ and lagged $A T$, and that lagged $A T$ explains most of the variance of $W T$. The fraction of $W T$ variance that is not explained by lagged $A T\left(1-R^{2}\right)$ can be related to the measurements uncertainties, or to unaccounted physical factors, such as discharge variability (Webb et al., 2003), groundwater inflows, stream shading or impoundments (Erickson and Stefan, 2000), but this unexplained fraction is always small. Figure 4 also shows that the best $R^{2}$ increase with Strahler order, as do the corresponding lags (see also Table 1), and that the variability of the best $R^{2}$ is larger when resulting from small lags, thus at low Strahler orders. These results, which support the choice of the model proposed in Eq. (1), are very consistent with the convergence of WT toward equilibrium temperature as water flows downstream, which implies that the equilibrium temperature, approximated by lagged $A T$, explains more and more of the variance of $W T$ as water flows downstream, thus as Strahler order increases.

For each of the 88 couples of $A T$-WT stations, we characterized the slope $a$ and y-intercept $b$ of the regression line between $W T$ and lagged $A T$, using the best lag, defined as above as the one that maximizes $R^{2}$. As Strahler order increases, the slope $a$ increases to values close to 1 , the $y$ intercept $b$ decreases, and the variability of these two parameters is markedly reduced (Fig. 5). Moreover, $a$ and $b$ are tightly related, as shown by their strong correlation coefficient $(R=0.91)$, and the scatter of this relationship does not exhibit a large dependence on Strahler orders (Fig. 6).

These regression analyses between observed $W T$ and lagged $A T$ are summarized in Table 1, which gives the means, for all the studied stations within the same Strahler order, of the best lags and corresponding $R^{2}$, and of the corresponding slopes $a$ and y-intercepts $b$, defining the best linear function of lagged $A T$. It also gives the means by Strahler order of interesting measures of the fit between observed $W T$ and these best linear functions of lagged $A T$. Root mean squared errors (RMSEs) range between 0.79 and $1.86^{\circ} \mathrm{C}$, with a mean of $1.18^{\circ} \mathrm{C}$, to be compared to a mean $W T$ of $12.62^{\circ} \mathrm{C}$ over the 88 couples of $A T$-WT stations. The mean RMSEs do not appear to depend on Strahler order, but mean WT temperature increases with Strahler order, so that the mean relative performance of the fitted relationships increases with stream order.

Biases are always negative and range between -0.56 and $0^{\circ} \mathrm{C}$, with a mean of $-0.18^{\circ} \mathrm{C}$ over the 88 couples of $A T$-WT stations. These biases can probably be attributed to departures from linearity of the actual relationship between WT and lagged AT. As shown by Mohseni et al. (1998), this relationship is generally S-shaped, with variations of $W T$ that are slower than the ones of lagged $A T$ at the two bounds of the temperature range. In particular, $W T$ decreases less that lagged $A T$ at low temperatures, as water freezing prevents $W T$ from dropping below $0^{\circ} \mathrm{C}$. In such a case, Eq. (1) underestimates $W T$, which can induce a negative bias. This behaviour is noticeable in some of the studied stations, and it 
(a)

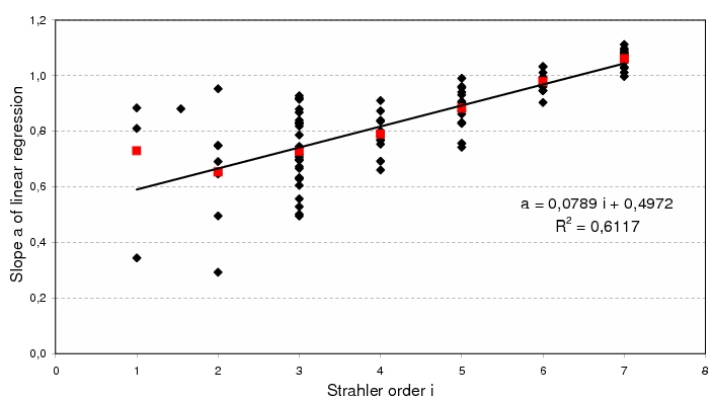

(b)

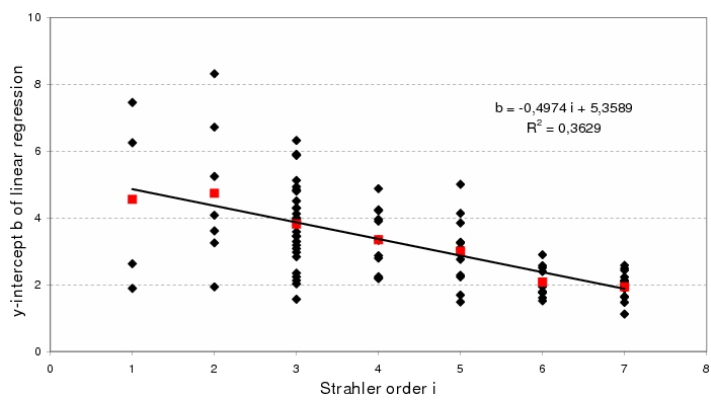

Fig. 5. Relationship to Strahler order of the slope $a$ and y-intercept $b$ of the linear regression between $W T$ and lagged $A T$, using the lag that maximizes the determination coefficient $R^{2}$. The black lines are the regression lines between the Strahler orders and the means of the slope and y-intercept for each Strahler order, represented by red squares. They are characterized by the linear regression equations and determination coefficients given in the plots.

might exist in all of them even if not clearly detectable within the noise of the relationship. The other departure from linearity, at high temperatures, conversely induces an overestimation of WT as predicted from Eq. (1), but this behaviour was not found in the Seine river basin, probably because it did not experience warm enough conditions during the analysed period.

The selected linear relationship is thus a satisfactory approximation of the actual S-shaped relationship if the temperature range is reduced enough to prevent the above inflexions from being significant, which is true of most stations in our case study. An implication of this choice for linearity is a loss of accuracy at the extreme bounds of the temperature range, even if compensation can arise in terms of bias between overestimated high temperatures and underestimated low temperatures. In the Seine River basin, however, the latter underestimation is dominant, which certainly explains a large part of the negative biases. Another possible explanation is related to thermal pollution, which can increase observed WT over the entire temperature range, and which certainly exists in the Seine River basin, especially at low Strahler orders, the most impacted by urbanization and industrialization.

In an attempt to generalize the model given in Eq. (1), and to reduce the work required to define the parameters for a couple of $A T-W T$ stations, we checked whether some of these parameters could be defined a priori based on the above re-

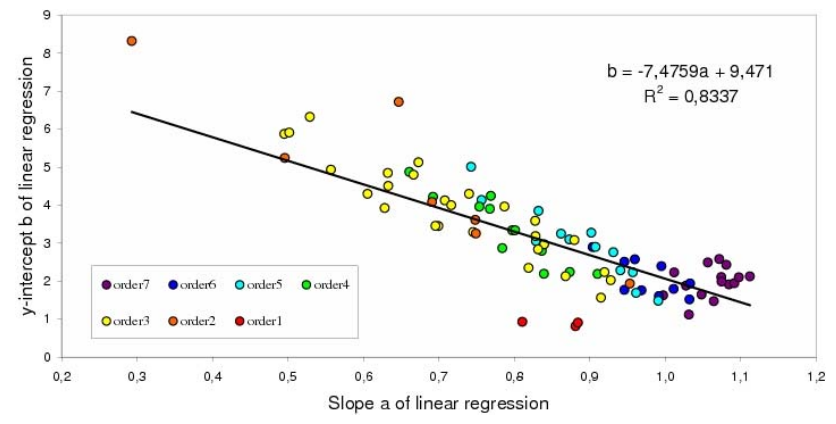

Fig. 6. Relationship between the slope $a$ and y-intercept $b$ of the linear regression between $W T$ and lagged $A T$, using the lag that maximizes the determination coefficient $R^{2}$. The color of the dots indicates the Strahler order at the WT measurement stations. The black line is the regression line between the slopes and y-intercepts, characterized by the displayed linear regression equation and determination coefficient.

sults. For each Strahler order, we selected, among the 6 lag values previously tested $(2,3,5,7,10$ and 15 days), the closest one to the mean best lag. We defined $a$ as the mean of the slopes corresponding to the selected lag, and we deduced $b$ from the equation of the regression line between $b$ and $a$ (Fig. 6). The resulting values of lag, $a$ and $b$ in Table 1 are used for all the $W T$ stations of a given Strahler order, using the $A T$ measurements from the closest station. The indicators of the fit between $W T$ calculated this way and observed WT compare very well with the same indicators applied to the relationships between observed $W T$ and the best linear functions of lagged $A T$, that use parameters that are optimized for each couple of $A T-W T$ stations. The determination coefficient $R^{2}$ are as good, and the biases are not markedly different $\left(-0.20^{\circ} \mathrm{C}\right.$ on average over the 88 couples of $A T-W T$ stations). The RMSEs are higher, especially at low Strahler orders, but the increase is moderate and the resulting RMSEs remain satisfactory, as illustrated by the mean RMSE of $1.45^{\circ} \mathrm{C}$ over the 88 couples of $A T$-WT stations.

\subsection{Implications regarding climate change}

Under the necessary assumption of their transferability to climate change conditions, these relationships can be used to deduce $W T$ change from $A T$ change under climate change. In particular, when $a=1$, the mean of $W T$ change over several years is equal to the one of $A T$, as the effect of the lag becomes negligible over long time scales. This property was used to simplify the problem of $W T$ change estimation from $A T$ change under climate change. Table 1 shows that $a$ is very close to 1 in streams with a Strahler order of 6 and 7. These are the main streams of the Seine River network (Fig. 1), where human and industrial density is by far the highest and where residence time in the river network has been long enough for phytoplankton biomass to have significantly developed (Garnier et al., 1995). These streams are 
Table 2. Simulations of discharge and water quality performed with RIVERSTRAHLER. ACT stands for "Actual (1991) point sources" and IWT stands for "Improved Wastewater Treatment", as can be assumed by 2050 . A2 and REF refer to the climate scenarios used to simulate runoff with the CLSM.

\begin{tabular}{llll}
\hline Label & Point sources & Runoff & $\Delta W T\left({ }^{\circ} \mathrm{C}\right)$ \\
\hline ACT & 1991 & REF (86-90) & 0 \\
ACT+A2-Tw & 1991 & A2 & 0 \\
ACT+A2 & 1991 & A2 & +3.3 \\
IWT & IWT (2050) & REF (86-90) & 0 \\
IWT+A2-Tw & IWT (2050) & A2 & 0 \\
IWT+A2 & IWT (2050) & A2 & +3.3 \\
\hline
\end{tabular}

thus very vulnerable to biogeochemical water quality problems, such as algal blooms, eutrophication and oxygen depletion.

Assuming that a lesser accuracy in $W T$ change could be accepted in smaller order streams, it was decided to generalize the simple case of $a=1$ to the entire river network. This offers the advantage of an easy spatialization, as local $A T$ changes, such as described in the 27 unit catchments used to subdivide the Seine watershed in the CLSM and RIVERSTRAHLER simulations, can be directly interpreted as $W T$ changes. A disadvantage of this simplification, however, is that it prevents from describing the seasonal variations of $W T$ change. AT change is higher in summer (Fig. 3), so that $W T$ change is underestimated during this season, when the biogeochemical processes are the most intense because of their dependence on temperature. This inaccuracy is offset in small order streams (Strahler order $<6$ ), where $a<1$, so that $W T$ change is overestimated if using $a=1$. Lower values in summer than those described under the assumption of linear relationship between $W T$ and lagged $A T$ might be realistic, however, because of the lesser variations of $W T$ with respect to $A T$ for extreme values of $A T$, leading to an S-shaped relationship, as revealed by Mohseni et al. (1998).

In conclusion, it is thought that the many uncertainties that accompany the transfer to climate change conditions of statistical relationships established under the present climate justify their simplified use. Therefore, the values of WT under climate change were deduced from their present time values (described by a sinusoidal annual cycle) by adding all the year long the mean increase in 2-m air temperature $\left(+3.3^{\circ} \mathrm{C}\right)$ between the reference climate $(1986-1990)$ and climate change scenario A2.

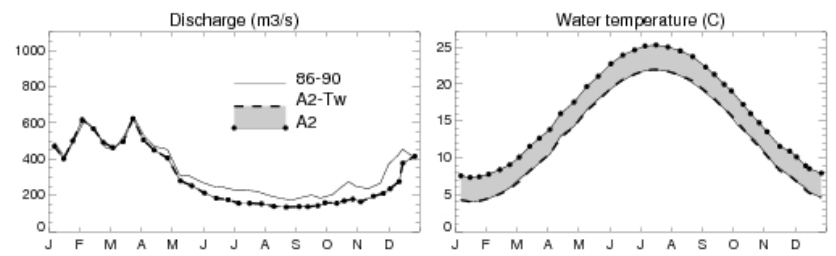

Fig. 7. Impact of climate change simulated by RIVERSTRAHLER on discharge and WT (interannual monthly means over 5 years) between the reference climate (1986-1990) and the two climate change scenarios: A2-Tw, where only discharge changes, and A2, where both discharge and water temperature change. The grey shade indicates the impact of water warming. The values are simulated in Paris, but are also representative for Conflans, as the differences in simulated runoff and WT between the two stations are negligible.

\section{Modelling of climate change impact on water quality}

\subsection{Description of the simulations}

Six simulations were performed with RIVERSTRAHLER to analyse the relative influence of water warming and discharge changes on the simulated parameters of water quality, and how this influence is modulated by nutrient and organic carbon loads (Table 2). Simulation ACT corresponds exactly to the validation simulation described in Sect. 3.3, with point source input of year 1991. Simulation ACT+A2 differs from $\mathrm{ACT}$ in that it accounts for the influence of climate change scenario A2 on runoff, as simulated by the CLSM (Sect. 4.3), and on $W T$, using the simplified model of $W T$ change described in Sect. 5.3. Simulation ACT+A2-Tw was designed to understand the role of water warming in the impact of climate change on the water quality simulated by RIVERSTRAHLER, and only keeps from climate change its impacts on runoff and river discharge, so that WT is the same as in simulation ACT. The corresponding impacts on river discharge and $W T$ in Paris are shown in Fig. 7. As runoff, discharge is mainly reduced during the low flow period, with a mean decrease of $-24 \%$ from May to December.

Simulation IWT differs from ACT by the point-source inputs to the streams, which are assumed to be reduced. As detailed in Ducharne et al. (2007), future point source pollution by 2050 , of both domestic and industrial origin, was estimated following the assumptions embedded in scenario SRES-A2 regarding demographic, economic and technologic changes. This led to reductions of 30 to $75 \%$ compared to 2000, depending on the pollutants. The technology efficiency, as estimated for 2050 from specialised technological prospective and experts interviews, was found to be the primary driver of this evolution. This scenario is a "business as usual" scenario as it follows the current trend to improved wastewater collection and treatment. This trend was already ongoing between 1991 and 2000, with the exception of nitrate. Overall, all point-source pollutants are reduced by 
(a) Paris
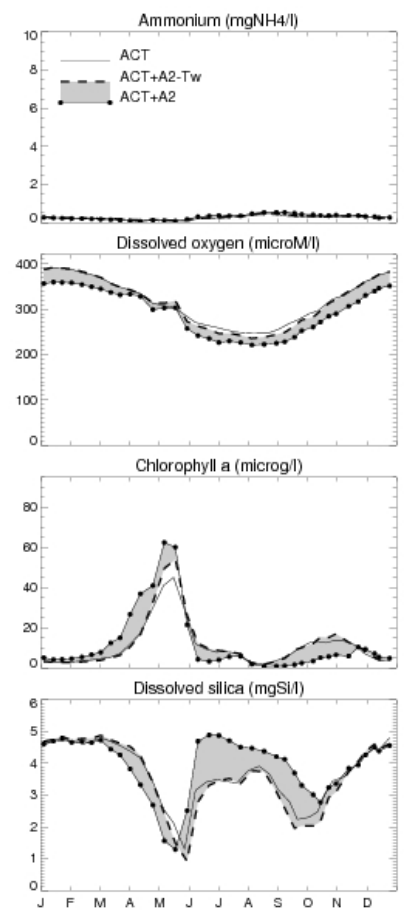

(b) Conflans

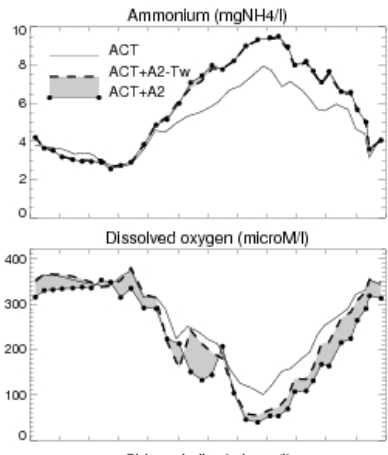

Chlorophyll a (microgll)

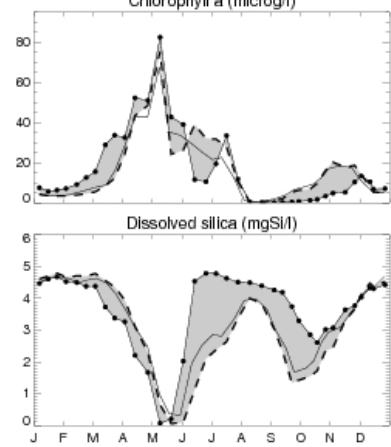

Fig. 8. Impact of climate change simulated by RIVERSTRAHLER on water quality in Paris and Conflans (interannual monthly means over 5 years), with point source input from 1991. Chlorophyll- $a$ is proportional to phytoplankton biomass (Garnier et al., 1995). The differences between simulations ACT and ACT+A2-Tw show the impact that arises from the changes in river discharge, and the differences between $\mathrm{ACT}+\mathrm{A} 2-\mathrm{Tw}$ and $\mathrm{ACT}+\mathrm{A} 2$, shaded in grey, show the impacts that are driven by the warming of the water column.

more than 75\% between simulation ACT, for "Actual (1991) point sources", and simulation IWT, for "Improved Wastewater Treatment". This reduction in point source inputs is also the only difference between simulations IWT+A2 and IWT $+\mathrm{A} 2-\mathrm{Tw}$ on the one hand, and simulations $\mathrm{ACT}+\mathrm{A} 2$ and $\mathrm{ACT}+\mathrm{A} 2-\mathrm{Tw}$ on the other hand.

All other boundary conditions to RIVERSTRAHLER are identical in all six simulations. They include all the diffuse sources to the river network. In particular, even if climate change significantly increases diffuse nitrate sources (Ducharne et al., 2007), this impact was neglected for simplicity, as these authors show that it has no subsequent influence on the other simulated terms of water quality, nitrate concentrations being already too high in present time simulations for ever being limiting. Photosynthetically active radiation in the water column is unchanged under climate change scenario A2, under the assumption that the high extinction coefficient prevents any significant change from solar radiation change. All indirect impacts of climate change were also neglected, such as possible adaptations of hydraulic management or land-use.

(a) Paris
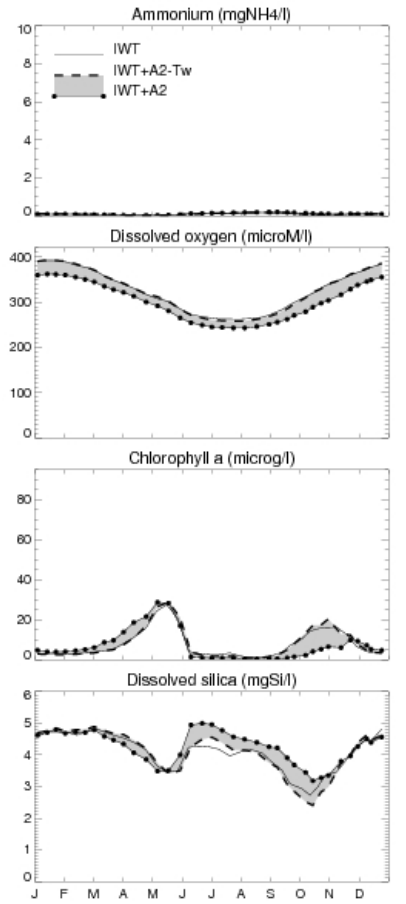

(b) Conflans

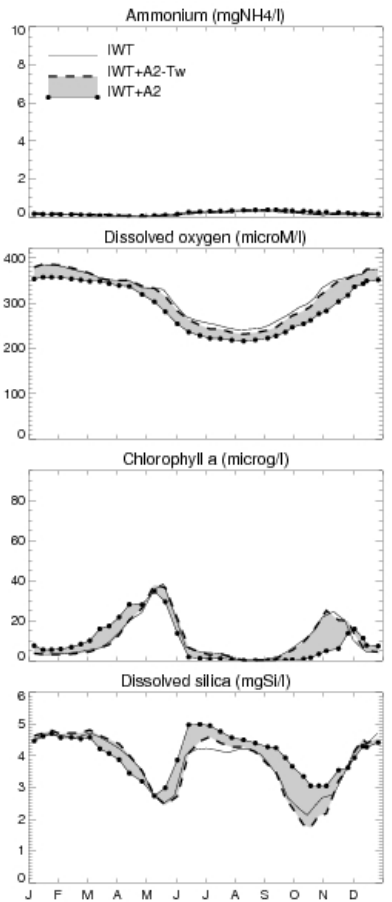

Fig. 9. Impact of climate change simulated by RIVERSTRAHLER on water quality in Paris and Conflans (interannual monthly means over 5 years), with reduced point source input as anticipated for 2050. Chlorophyll- $a$ is proportional to phytoplankton biomass (Garnier et al., 1995). The differences between simulations IWT and IWT+A2-Tw show the impact that arises from the changes in river discharge, and the differences between IWT+A2-Tw and IWT $+\mathrm{A} 2$, shaded in grey, show the impacts that are driven by the warming of the water column.

\subsection{Results}

The impact of climate change scenario A2 on the riverine biogeochemical processes described by the model RIVERSTRAHLER is compared in Paris and Conflans. These two stations are on the Seine River, at Strahler order 7, and their main difference is related to massive point source input between them, in particular from the Achères WTP (Sect. 3.3). The water quality at Conflans is representative of the one downstream from the Achères WTP, as shown by the comparison with the results simulated at Poses, the most downstream station before entering the estuary (Ducharne et al., 2007), and the water quality in Paris is representative of the fraction of the upstream river network where phytoplankton develops. In smaller streams, microbiological biomass and organic carbon concentrations are very limited, and water quality issues are mainly related to nitrate diffuse pollution, which is not addressed in this paper.

In both Figs. 8 and 9, the changes in ammonium concentration are representative of the ones undergone by the point 
source effluents from the WTPs, including phosphate and organic carbon. Figure 8 compares the impact of climate change in Paris and Conflans, with point sources of 1991. The clear increase in nutrient and organic carbon concentrations between these two stations results from massive point source input at Achères, and it is enhanced under climate change. This impact is explained by reduced dilution owing to reduced discharge, as shown by the similarity between simulations $\mathrm{ACT}+\mathrm{A} 2-\mathrm{Tw}$ and $\mathrm{ACT}+\mathrm{A} 2$. The increase in ammonium and organic carbon concentration under climate change combine in Conflans to enhance oxygen depletion. The comparison of simulations ACT+A2-Tw and ACT $+\mathrm{A} 2$ confirms the dominant influence of discharge change on this impact. The latter is augmented by the effect of water warming, which reduces the diffusivity of oxygen in the water column. This impact is present all the year long, and also in Paris, whereas the impact of reduced dilution is limited to low flow periods, and almost inexistent in absence of point source inputs.

Climate change also impacts phytoplankton biomass. In both stations, this effect is mostly due to water warming (Fig. 8). During the growth period (January to April), biomass is higher under climate change, because growth is enhanced at higher temperatures. During the rest of year, when phytoplankton biomass is smaller because the loss rate, induced by numerous loss factors (zooplankton, viruses and benthic molluscs) is larger than the growth rate, phytoplankton biomass is reduced under climate change. The reason is that temperature enhances the loss rate more than the growth rate. Phytoplankton is largely dominated in the Seine River network by siliceous algae, Diatoms, which take up dissolved silica as a nutrient. Therefore, the concentration of the latter constitutes an integrated indicator of the upstream phytoplankton growth, and the above two phases are clearly illustrated by the dissolved silica concentrations. They are separated by the minimum of silica concentration, and display an opposite response to climate change, with decreased concentrations during the enhanced growth period, and increased concentration afterwards, when growth is inhibited by enhanced loss factors. Dissolved silica concentrations also show that, during this latter phase, the overall decrease in phytoplankton biomass results from two opposed effects, the impact of warming on loss factors hiding a smaller growth increase related to discharge reduction (as revealed by the differences between simulations ACT and ACT+A2-Tw), by means of increased nutrient concentrations (as illustrated for ammonium), or increased residence time, or both.

The situation is very different when point sources are reduced (Fig. 9). The magnitude of the simulated reduction is illustrated by the ammonium concentrations in Conflans, when comparing simulations with point source input of 1991 (Fig. 8) and simulations with improved wastewater treatment as assumed by 2050 (Fig. 9). As a result from this marked reduction in point source inputs, nutrient and organic carbon concentrations in simulation IWT are no more different be- tween Conflans and Paris, and so are the other terms of water quality. In addition, phytoplankton biomass and silica depletion are reduced (by nutrient limitation) between ACT and IWT, as are oxygen deficits in Conflans, because the smaller concentrations in organic carbon and ammonium limit respiration by heterotrophic and nitrifying bacteria. Starting from this much better water quality, the impact of climate change is smaller than with point source input of 1991. In both Conflans and Paris, this impact is similar to the one described in Paris with ACT as a reference simulation. In particular, the impact of reduced discharge and dilution is almost negligible in both stations.

\section{Discussion and conclusions}

This paper presents the development, in the Seine River basin, of a statistical model describing water temperature $(W T)$ as a linear function of the lagged moving average of air temperature (lagged $A T$ ). A novel result compared to previous work is the evidence that the parameters of this model depended on Strahler stream order, as a result of the convergence of WT toward equilibrium temperature as water flows downstream. This allowed us to define these parameters a priori from the sole Strahler order, which constitutes an interesting advance to generalize such statistical models. As discussed in Sect. 5.1, the main limitation of the statistical regression approach is its transferability to other conditions than prevailing for the characterization of its parameters. Therefore, the proposed generalized model is only valid in the Seine river basin. If the relationship to Strahler order was confirmed in other watersheds, the parameters would still need to be characterized locally, as they implicitly account for all the local characteristics that are not explicated by the model.

Transferability is also an issue when addressing climate change, which shall lead to air temperatures that have never been experienced in history. In particular, there is evidence that the air-water temperature relationship fails to remain linear at the extreme bounds of the air temperature range, either below $0^{\circ} \mathrm{C}$, as water freezes instead of cooling, or above ca. $25^{\circ} \mathrm{C}$, the proposed explanation being based on the non linear dependence of radiative and evaporative cooling to temperature. These non-linearities induce an S-shaped relationship that can be described by a sigmoid function (e.g. Mohseni et al., 1998). Our analysis did not reveal that the relationship between $W T$ and lagged $A T$ departed from linearity at high temperatures, which may be related to the lagged moving average, as suggested by Webb et al. (2003). Further validation is required to address this concern, in particular using data from 2003, which had the warmest summer ever recorded in the Seine basin, as in most of Europe. An interesting perspective would then be the inclusion of this $W T$ model directly in RIVERSTRAHLER, to dynamically 
describe the spatial-temporal variations of water temperature in response to meteorological forcing.

This paper finally illustrates the usefulness of the above WT model, coupled to validated physically-based models, to explore the possible evolutions of biogeochemical water quality. The simulated results highlight how the latter is submitted to three main driving factors, namely river discharge, water temperature, and inputs to the river network, essentially controlled by human activities. The evolution of the biogeochemical water quality simulated by RIVERSTRAHLER is shown to result from complex interactions between these three factors, the evolution of which are all controlled by human activities, either directly or indirectly (e.g. climate change). With high point source input (as in Conflans with point source input of 1991), climate change impact is dominated by the one of water warming for phytoplankton biomass and dissolved silica, and by the one of discharge reduction for oxygen, organic carbon and other nutrients. With lower point sources (as in Paris, or assuming improved wastewater treatment), the impact of discharge reduction is negligible, and climate change impact is almost entirely due to water warming. These relative effects could probably be different if discharge changes were higher. In any case, the impacts of climate change increase with the magnitude of point source inputs.

The proposed model of water temperature could as well be used to explore the impact of climate change on other aspects of water quality. In particular, ample evidence has now been gathered about ongoing changes in the structure of riverine ecosystems that can be attributed to climate change (e.g. Daufresne and Boet, 2007). Modelling would permit to propagate these trends to the future, as already attempted by Eaton and Scheller (1996) for instance, who found that climate warming could reduce the habitat of cool but also warm water fishes..

Acknowledgements. This work benefited from support by the French research programmes PIREN-Seine and Gestion et Impact du Changement Climatique of the Ministère de l'Ecologie et du Développement Durable. This work would not have been possible without the data provided by Météo-France, the Agence de l'Eau Seine-Normandie, and the Institution Interdépartementale des Barrages Réservoirs du Bassin de la Seine. Marilyse Latu was instrumental to perform the regression analyses shown in this paper. The author would also like to thank Daniel Brunstein, Sylvain Théry and Sidonie Christophe for their help with Arcview, and Gilles Billen and Josette Garnier for fruitful discussions about the RIVERSTRAHLER model.

Edited by: S. Barles

\section{References}

AESN: Les bassins de la Seine et des cours d'eau normands - Hydrologie générale et conclusions, Tome 1, Fascicule 6, Agence de l'Eau Seine-Normandie, Nanterre, 1976.

Arnell, N. W., Liu, C., Compagnucci, R., da Cunha, L., Hanaki, K., Howe, C., Mailu, G., Shiklomanov, I., and Stakhiv, E.: Hydrology and water resources, in: Climate Change 2001: Impacts, Adaptation, and Vulnerability, edited by: McCarthy, J. J., Canziani, O., Leary, N. A., Dokken, D. J., and White, K. S., Contribution of Working Group II to the Third Assessment Report of the Intergovernmental Panel on Climate Change, Cambridge University Press, Cambridge, 191-233, 2001.

Beven, K., and Kirkby, M. J.: A physically based variable contributing area model of basin hydrology, Hydrol. Sci. Bull., 24, 43-69, 1979.

Billen, G., Garnier, J., and Hanset, P.: Modelling phytoplankton development in whole drainage networks: The RIVERSTRAHLER model applied to the Seine River system, Hydrobiol., 289, 119137, 1994.

Billen, G., Garnier, J., Ficht, A., and Cun, C.: Modelling the response of water quality in the Seine Estuary to human activity in its watershed over the last 50 years, Estuaries, 24, 977-993, 2001.

Billen, G., Garnier, J., Mouchel, J. M., and Silvetsre, M.: The Seine system: Introduction to a multidisciplinary approach of the functioning of a regional river system, Science of The Total Environment, 375, 1-12, doi:10.1016/j.scitotenv.2006.12.001, 2007.

Caissie, D., El-Jabi, N., and St-Hilaire, A.: Stochastic modelling of water temperatures in a small stream using air to water relations, Can. J. Civ. Eng., 25, 250-260, 1998.

Daufresne, M. and Boet, P.: Climate change impacts on structure and diversity of fish communities in rivers, Global Change Biol., 13, 2467-2478, doi:10.1111/j.1365-2486.2007.01449.x, 2007.

Ducharne, A., Koster, R. D., Suarez, M., Stieglitz, M., and Kumar P.: A catchment-based approach to modeling land surface processes in a GCM - Part 2: Parameter estimation and model demonstration, J. Geophys. Res., 105(D20), 24823 $24838,2000$.

Ducharne, A., Golaz, C., Leblois, E., Laval, K., Polcher, J., Ledoux, E., and de Marsily, G.: Development of a high resolution runoff routing model, calibration and application to assess runoff from the LMD GCM, J. Hydrol., 280, 207-228, 2003.

Ducharne, A., Baubion, C., Beaudoin, N., Benoit, M., Billen, G., Brisson, N., Garnier, J., Kieken, H., Lebonvallet, S., Ledoux, E., Mary, B., Mignolet, C., Poux, X., Sauboua, E., Schott, C., Théry, S., and Viennot, P.: Long term prospective of the Seine River system: Confronting climatic and direct anthropogenic changes, Sci. Total Environ., 375, 292-311, doi:10.1016/j.scitotenv.2006.12.011, 2007.

Durand, Y., Brun, E., Merindol, L., Guyomarc'h, G., Lesaffre, B., and Martin, E.: A meteorological estimation of relevant parameters for snow models, Ann. Glaciol., 18, 65-71, 1993.

Eaton, J. G. and Scheller, R. M.: Effects of Climate Warming on Fish Thermal Habitat in Streams of the United States, Limnol. Oceanogr., 41(5), 1109-1115, 1996.

EEA: Corine Land Cover (CLC90), European Environment Agency, http://dataservice.eea.europa.eu/dataservice/ metadetails.asp?id=188, 1996.

Erickson, T. R. and Stefan, H. G.: Linear air/water temperature cor- 
relations for streams during open water periods, J. Hydrol. Eng., American Society of Civil Engineers, 5, 317-321, 2000.

Garnier, J., Billen, G., and Coste, M.: Seasonal succession of Diatoms and Chlorophycae in the drainage network of the River Seine : Observations and modelling, Limnol. Oceanogr., 40, 750-765, 1995.

Garnier, J., Billen, G., Palfner, L.: Understanding the oxygen budget and related ecological processes in the river Mosel: the RIVERSTRAHLER approach, Hydrobiol., 410, 151-166, 1999.

Gibelin, A. L. and Déqué, M.: Anthropogenic climate change over the Mediterranean region simulated by a global variable resolution model, Clim. Dynam., 20, 327-339, 2003.

Hanratty, M. P. and Stefan, H. G.: Simulating climate change effects in a Minnesota agricultural watershed, J. Environ. Qual., 27, 1524-1532, 1998.

Houghton, J. T., Ding, Y., Griggs, D. J., Noguer, M., van der Linden, P. J., Dai, X., Maskell, K., and Johnson, C. A.: Climate Change 2001: The Scientific Basis - Contribution of Working Group I to the Third Assessment Report of IPCC, Cambridge University Press, 2001.

Koster, R. D., Suarez, M., Ducharne, A., Stieglitz, M., and Kumar, P.: A catchment-based approach to modeling land surface processes in a GCM - Part 1: Model structure, J. Geophys. Res., 105(D20), 24 809-24 822, 2000.

Ledoux, E., Gomez, E., Monget, J. M., Viavattene, C., Viennot, P., Ducharne, A., Benoit, M., Mignolet, C., Schott, C., and Mary B.: Agriculture and Groundwater Nitrate Contamination in the Seine Basin. The STICS-MODCOU modelling chain, Sci. Total Environ., 375, 33-47, doi:10.1016/j.scitotenv.2006.12.002, 2007.
Meybeck, M., de Marsily, G., and Fustec, E.: La Seine en son bassin. Fonctionnement écologique d'un système fluvial anthropisé, Elsevier, Paris, France, 1998.

Mohseni, O., Stefan, H. G., and Erickson, T. R.: A non linear regression model for weekly stream temperatures, Water Resour. Res., 10, 2685-2692, 1998.

Mohseni, O. and Stefan, H. G.: Stream temperature/air temperature relationship: a physical interpretation, J. Hydrol., 218, 128-141, 1999.

Stefan, H. G. and Preud'homme, E. B.: Stream temperature estimation from air temperature, Water Resour. Bull., 29, 27-45, 1993.

Strahler, A. H.: Quantitative analysis of watershed geomorphology, Geophys. Union Trans., 38, 913-920, 1957.

Vannote, R. L., Minshall, G. W., Cummins, K. W., Sedell, J. R., and Cushing, C. E.: The river continuum concept, Can. J. Aquat. Sci., 37, 130-137, 1980.

Webb, B. W. and Nobilis, F.: Long-term perspective on the nature of the air-water temperature relationship: a case study, Hydrol. Process., 11, 137-147, 1997.

Webb, B. W., Clack, P. D., and Walling, D. E.: Water-air temperature relationships in a Devon system and the role of flow, Hydrol. Process., 17, 3069-3084, 2003. 